\title{
Toxinas killer e produção de enzimas por Candida albicans isoladas da mucosa bucal de pacientes com câncer
}

\author{
Killer toxin sensitiviy and production of enzymes by \\ Candida albicans isolated from the oral mucosa \\ of patients with cancer
}

Elida Elias de O liveira, Soraya Cristina Silva, Ailton José Soares, Cecília Attux, Brice Cruvinel e Maria do Rosário Rodrigues Silva

\begin{abstract}
Resumo Infecções oportunistas da cavidade bucal são primariamente causadas por fungos do gênero Candida e freqüentemente ocorrem em pacientes com câncer que estão sobtratamento quimioterápico e antibacteriano. De 44 amostras coletadas da mucosa oral de pacientes com câncer, observou-se o isolamento de 25 leveduras do gênero Candida em cultivo realizado em ágar Sabouraud-dextrose. Foram identificados Candida albicans em 24 $(96 \%)$ isolados e C. krusei em 1 (4\%). As características fenotípicas das amostras de Candida albicans mostraram que todos os isolados foram fortemente proteolíticos, capazes de produzir fosfolipases e possuíam os biotipos caracterizados como $811(95,8 \%)$ e 511 (4,2\%) em relação a susceptibilidade às toxinas killer.
\end{abstract}

Palavras-chaves: C. albicans. Câncer. Fosfolipase. Proteinase. Toxinas killer.

\begin{abstract}
Opportunistic infections of the oral cavity are primarily caused by Candida and frequently occur in patients with cancer who are undergoing chemotherapy and antibiotic treatment. Of the specimens received from the oral mucosa of 44 patients with cancer, 25 (56.8\%) yielded Candida on culture in Sabouraud agar. Twenty four of these isolates were identified as C. albicans (96\%) and 1 as C. krusei (4\%). The phenotypic characteristics of these isolates showed that all of them were strongly proteolytic, had a high ability to produce phospholipase, and presented the byotypes characterized as 811 (95.8\%) and 511 (4.2\%) in terms of susceptibility to killer toxins.
\end{abstract}

Key-words: C. albicans. Cancer. Phospholipase. Proteinase. Killer toxins.

\footnotetext{
Trabalho realizado no Departamento de Microbiologia, Imunologia, Parasitologia e Patologia do Instituto de Patologia Tropical e Saúde Pública da Universidade Federal de Goiás, Goiânia, GO.

Endereço para correspondência: Prof ${ }^{a}$ Maria do Rosário Rodrigues Silva Disciplina de Micologia. R Delenda de Resende de Melo, s/nº Setor Universitário 74605-050 Goiânia, GO.

Fax (062) 2023066.

Recebido para publicação em 18/12/97.
} 
Candida albicans, levedura pertencente à biota normal humana, é freqüentemente encontrada como causadora de lesões em pacientes com câncer 917.

Terapia com corticóides ou antineoplásicos e o uso de dispositivos intravenosos contribuem para a ocorrência de candidíase. A aderência da levedura à superfície celular, a formação de tubo germinativo com conseqüente desenvolvimento da forma filamentosa, a variabilidade fenotípica switching, a produção de toxinas e enzimas extracelulares constituem os fatores mais importantes para o desencadeamento de infecção por $C$. albicans 451314 18. A produção de fosfolipase é considerada um fator importante para o processo de infecção, variando conforme a amostra. Essa enzima, localizada na superfície da levedura e na extremidade do tubo germinativo, atua pela hidrólise dos fosfolipídeos, dando origem aos lisofosfolipídeos que causam dano à célula epitelial20. Segundo Samaranayake, 198424, entre as espécies de Candida, apenas C. albicans é capaz de produzir fosfolipase.

O efeito proteolítico de amostras de $C$. albicans foi demonstrado pela primeira vez por Staib et al, 196526. Esta enzima hidrolítica tem sido observada em sobrenadante de cultura e no citoplasma de blastoconídios de C. albicans. A proteinase extracelular produzida por diferentes espécies de Candida é capaz de degradar vários substratos, tais como: queratina, colágeno, albumina, fibronectina, hemoglobina, cadeia pesada de imunoglobulina e proteínas de matriz extracelular7 1023 . Enzimas proteolíticas foram encontradas em isolados de C. albicans, C. tropicalis e C. parapsilosis obtidas de várias amostras clínicas22.

Desde a década de 70, além do estudo de enzimas participantes do processo infeccioso, vários autores passaram a caracterizar as leveduras quanto ao fenômeno de produção de compostos proteicos denominados toxinas killer, observado em espécies dos gêneros Candida, Cryptococcus, Torulopsis e Trichosporon. O fenômeno killer é útil na diferenciação de leveduras dentro da própria espécie, podendo ser usado como marcador epidemiológico 1127.

O presente estudo tem como objetivo verificar a produção de fosfolipase e proteinase por Candida albicans isoladas de lesões de mucosa bucal de pacientes com câncer e ainda caracterizar estas linhagens através do fenômeno killer.

\section{MATERIAL E MÉTODOS}

Pacientes e isolados. Foram estudados materiais provenientes da mucosa bucal de 44 pacientes com câncer internados nas enfermarias de Pediatria, Cabeça e Pescoço e Unidade de Terapia Intensiva do Hospital Araújo Jorge, em Goiânia, GO, durante o período de novembro de 1996 a junho de 1997. Os materiais foram colhidos de lesões pseudo-membranosas esbranquiçadas com quadro clínico semelhante ao de candidíase através de swab esterililizado. O material coletado foi colocado em solução fisiológica esterilizada $(0,85 \%)$ e, posteriormente semeado em ágar Sabouraud dextrose com cloranfenicol mantido à temperatura de $25^{\circ} \mathrm{C}$ e examinado diariamente por um período de 15 dias.

As leveduras isoladas foram identificadas através da formação de tubo germinativo, produção de clamidoconídios e provas de assimilação e fermentação de hidratos de carbono segundo Kreger-van Ryj, 198412.

Pesquisa de exoenzimas. Fosfolipase. A produção de fosfolipase foi verificada segundo Price et al, 198220. Colônias de C. albicans com crescimento de 48 horas em ágar Sabouraud dextrose foram inoculadas em pontos eqüidistantes nas placas de ágar fosfolipase com emulsão de ovo a $50 \%$ em solução fisiológica. $\mathrm{O}$ ágar fosfolipase contém peptona$10 \mathrm{~g}$, glicose- $30 \mathrm{~g}$, cloreto de sódio- $57,3 \mathrm{~g}$, cloreto de cálcio- $0,55 \mathrm{~g}$, ágar- $20,0 \mathrm{~g}$ e água destilada$1000 \mathrm{ml}$. A leitura do teste foi realizada após 4 dias de incubação a $37^{\circ} \mathrm{C}$, sendo considerado como positivo a produção de zona opaca de precipitação ao redor da colônia. A atividade enzimática $(\mathrm{Pz})$ foi medida através da razão entre o diâmetro da colônia e o diâmetro da colônia mais a zona de precipitação. Quanto menor o valor de $\mathrm{Pz}$, maior a atividade enzimática, sendo os resultados apresentados em códigos: valor 1 quando $\mathrm{Pz}=1,0$ (ausência de atividade enzimática), valor 2 quando $0,64<\mathrm{Pz}>1,0$ (atividade enzimática positiva) e valor 3 quando $\mathrm{Pz} \leq 0,63$ (atividade enzimática fortemente positiva).

Proteinase. A produção de proteinase foi verificada segundo Ruchel et al, 198221. O fenômeno foi observado a partir de amostras de C. albicans cultivadas por 24 horas em ágar Sabouraud dextrose a $25^{\circ} \mathrm{C}$ inoculadas em pontos eqüidistantes em placas de ágar proteinase (mistura de yeast carbon base$11,7 \mathrm{~g}$; albumina bovina fração $\mathrm{V}-2,0 \mathrm{~g}$; protovit$2,5 \mathrm{ml}$ e água destilada- $100 \mathrm{ml}$ esterilizados em 
filtros de Millipore de $0,22 \mu \mathrm{m}$ de diâmetro adicionada de ágar- $15 \mathrm{~g}$ e água destilada- $900 \mathrm{ml}$ esterilizados por autoclave a $120^{\circ} \mathrm{C}$ durante 15 minutos).

As placas foram incubadas durante dois dias a $37^{\circ} \mathrm{C}$ e a leitura da atividade enzimática $(\mathrm{Pz})$ foi realizada usando-se o mesmo esquema da atividade para fosfolipase.

Toxinas killer. O fenômeno foi verificado segundo Polonelli et al, 198319. Os isolados em estudo foram cultivados por 24 horas em ágar Sabouraud modificado (peptona-10g, dextrose$20 \mathrm{~g}$, ácido cítrico-19,2g, fosfato de potássio bibásico-34,8g, ágar-20,0g e água destilada qsp para $1000 \mathrm{ml}$ ajustado a $\mathrm{pH} 4,5)$. Um (1) $\mathrm{ml}$ de suspensão de $C$. albicans correspondente a escala 3 de McFarland foi vertida em placas de Petri esterilizadas e, em seguida adicionadas de meio de ágar Sabouraud modificado acrescido de azul de metileno (30mg). Após a solidificação da suspensão e meio de cultura fez-se o inóculo na superfície do meio em pontos eqüidistantes das toxinas padrão $\mathrm{K} 1$ a $\mathrm{K} 9$, correspondendo respectivamente à Hansenula $s p$ (Stumm-
1034), Pichia sp (Stumm-1035), Hansenula anomala (Um-Milano), Hansenula anomala (CBS-5759), Hansenula anomala (AhearnUN866), Hansenula californica (Ahearn-WC40), Hansenula canadensis (Ahearn-WC41), Hansenula dimennae (Ahearn-WC44), Hansenual mrakii (Ahearn-WC51). Estas nove cepas padrão procedentes da Universidade do Chile foram gentilmente cedidas pelo Instituto de Ciências Biomédicas da USP.

A leitura foi realizada 72 horas após incubação a $25^{\circ} \mathrm{C}$ e foram considerados sensíveis (+), os cultivos que apresentaram halo incolor e/ou zona de inibição com colônias azuis ao redor dos isolados "padrão", e como resistentes os cultivos que apresentaram crescimento ao redor das cepas "padrão".

Os resultados de sensibilidade às toxinas killer foram designados pelo esquema proposto por Polonelli et al, 198319, composto por 3 dígitos, sendo que cada um representa a combinação dos resultados obtidos pelo conjunto de 3 cepas padrão como mostra a Tabela 1.

Tabela 1 - Codificação do Sistema killer.

\begin{tabular}{|c|c|c|c|c|c|c|c|c|c|c|c|}
\hline \multicolumn{4}{|c|}{ Atividade do $1^{\circ}$ triplet } & \multicolumn{4}{|c|}{ Atividade do $2^{\circ}$ triplet } & \multicolumn{4}{|c|}{ Atividade do $3^{\circ}$ triplet } \\
\hline K1 & $\mathrm{K} 2$ & K3 & Código & K4 & K5 & K6 & Código & K7 & K8 & K9 & Código \\
\hline+ & + & + & 1 & + & + & + & $1^{*}$ & + & + & + & $1^{*}$ \\
\hline+ & + & - & 2 & + & + & - & 2 & + & + & - & 2 \\
\hline+ & - & + & $3^{*}$ & + & - & + & 3 & + & - & + & 3 \\
\hline - & + & + & 4 & - & + & + & 4 & - & + & + & 4 \\
\hline+ & - & - & 5 & + & - & - & 5 & + & - & - & 5 \\
\hline- & + & - & 6 & - & + & - & 6 & - & + & - & 6 \\
\hline- & - & + & 7 & - & - & + & 7 & - & - & + & 7 \\
\hline- & - & - & 8 & - & - & - & 8 & - & - & - & 8 \\
\hline
\end{tabular}

* biotipo 311.

\section{RESULTADOS}

Leveduras do gênero Candida foram isoladas em $25(56,8 \%)$ dos 44 pacientes examinados. Os testes de identificação como produção de tubo geminativo, produção de clamidoconídios e provas de assimilação de hidratos de carbono, permitiram a identificação de 24 (96\%) C. albicans e 1 (4\%), C. krusei.
As 24 amostras de C. albicans estudadas apresentaram-se fortemente produtores de fosfolipase e de proteinase, sendo que a atividade enzimática de proteinase variou de 0,12 a 0,37, enquanto para fosfolipase houve uma maior variação, de 0,12 a 0,61 . Os valores de proteinase e de fosfolipase encontram-se na Tabela 2.

Tabela 2 - Valores de proteinase de fosfolipase de 24 isolados de C. albicans da mucosa bucal de pacientes com câncer .

\begin{tabular}{lcc}
\hline & Proteinase & Fosfolipase \\
\hline Variação de $\mathrm{Pz}^{*}$ & $0,12-0,37$ & $0,12-0,61$ \\
Média de $\mathrm{Pz}^{*}$ & 0,21 & 0,34 \\
\hline${ }^{*} \mathrm{Pz}$ ativa
\end{tabular}

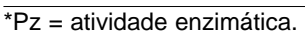


Pela sensibilidade das amostras de C. albicans isoladas da mucosa bucal de pacientes com câncer às 9 toxinas killer pudemos revelar dois biotipos: 811 e 511 , que ocorreram em $95,8 \%$ e $4,2 \%$ dos isolados, respectivamente.

\section{DISCUSSÃO}

Infecções fúngicas nosocomiais são causas importantes de morbidade e ocasionalmente de mortalidade. Em 1995 Jarvis9, em um estudo epidemiológico realizado de 1980 a 1990, analisando 180 diferentes hospitais, verificou que $72,1 \%$ das infecções fúngicas eram devidas às espécies de Candida.

Em pacientes imunocomprometidos que apresentam granulocitopenia e em uso de quimioterapia antineoplásica, há um maior risco de infecções por Candida ${ }^{8}$. Lesões da mucosa bucal por espécies de Candida especialmente C. albicans são freqüentes nesses pacientes. Nas amostras coletadas da mucosa bucal dos 44 indivíduos com câncer do Hospital Araújo Jorge de Goiânia-GO, 25 (56,8\%) possuíam lesões por Candida, sendo isoladas 24 (96\%) C. albicans e 1 (4\%) C. krusei.

Todas as amostras de $C$. albicans isoladas da mucosa bucal de pacientes com câncer estudadas neste trabalho apresentaram-se com um alto nível de produção de proteinase e fosfolipase, exibindo valores semelhantes entre as várias linhagens. Vários investigadores têm demonstrado a presença da fosfolipase em isolados clínicos de C. albicans ${ }^{123}$. Considerandose que outras espécies de Candida apresentam estruturas semelhantes às de $C$. albicans, mas não são capazes de produção de fosfolipases, é plausível que estas enzimas provavelmente se relacionem com a patogenicidade do isolado 24 .
A relação de virulência a proteinase foi demonstrada por Kwon-Chung et al, 198513, que verificaram um maior período de sobrevivência entre camundongos injetados com mutantes de culturas de $C$. albicans com menor produção de proteinase do que das cepas mãe com grande produção desta enzima. Isolados que secretam proteinase possuem maior poder de invasão aos tecidos do hospedeiro, pois aderem-se com maior facilidade às células epiteliais 61825 . Os resultados obtidos no trabalho permitem postular que o grande número de lesões observados na mucosa bucal dos pacientes com câncer seja decorrente de fatores inerentes ao hospedeiro, como também das características exibidas pelos isolados.

$O$ teste de sensibilidade às toxinas killer mostrou que isolados de mucosa bucal de pacientes com câncer são capazes de expressar na sua maioria apenas um biotipo. Entre os 24 isolados de $C$. albicans estudados, 23 (95,8\%) mostraram-se com o biotipo 811, o que significa resistência às toxinas $\mathrm{K} 1, \mathrm{~K} 2$ e $\mathrm{K} 3$. O sistema killer segundo Morace et al, 198416 e Merz, 199015 pode ser usado como marcador epidemiológico em casos de infecções nosocomiais causadas por leveduras patogểnicas. Isolados de $C$. albicans podem sofrer alterações fenotípicas, por isto, para estudos epidemiológicos de infecções por Candida, obtidas de diferentes materiais clínicos, além das características fenotípicas, devem ser consideradas as características genotípicas expressas pelos isolados.

\section{REFERÊNCIAS BIBLIOGRÁFICAS}

1. Banno Y, Yamada T, Nozawa Y. Secreted phospholipases of the dimorphic fungus Candida albicans: separation of three enzymes and some biological properties. Sabouraudia 23:47-54, 1985.

2. Barreto de Oliveira MT. Leveduras isoladas da mucosa bucal de portadores sadios, pacientes com SIDA e neoplasias. Produção de exoenzimas e tipagem das amostras de Candida albicans. Dissertação de Mestrado, Instituto de Ciências Biomédicas da Universidade de São Paulo, São Paulo, 1993.

3. Candido RC. Candida albicans: marcadores epidemiológicos em amostras isoladas de diferentes materiais biológicos. Tese de Doutorado, Escola Paulista de Medicina, São Paulo, 1991.
4. Chakrabarti A, Navak N, Talwar P. In vitro proteinases production by Candida species. Mycopathologia 114:163-168, 1991.

5. Delgado W, Aguirre J.M. Las micosis orales en la era del sida. Revista lberoamericana de Micologia 14:1422, 1997.

6. Ghannoum M, Abu-Elteen KH. Correlative relationship between proteinase production, adherence and pathogenicity of various strains of Candida albicans. Journal of Medical and Veterinary Mycology 24:407413, 1986.

7. Hattori JE, Yoshiura K, Negi M, Ogawa H. Keratinolytic proteinase produced by Candida albicans Sabouraudia 22:175-183, 1981. 
8. Hoppe JE, Klingebiel T, Niethammer D. Orointestinal yeast colonization of pediatric bone marrow transplant recipients:surveillance by quantitative culture and serology. Mycoses 38:51-57, 1995.

9. Jarvis RW. Epidemiology of nosocomial fungal infections, with emphasis on Candida species. Clinical Infectious Diseases 20:1526-1530, 1995.

10. Kaminishi $H$, Hagihara $Y$, Hayashi $S$, Cho T. Isolation and characteristics of collagenolytic enzyme produced by Candida albicans. Infectious Immunology 53:312316, 1986.

11. Kandel JS, Stern TA. Killer phenomenon in pathogenic yeasts. Antimicrobiology Agents Chemotherapy 15:568-571, 1979.

12. Kreger-van Rij NJW. The yeast: a taxonomic study. Editora Elsevier, Amsterdam, 1984.

13. Kwon-Chung KJ, Lehman D, Good C, Magee PT. Genetic evidence for role of extracellular proteinase in virulence of Candida albicans. Infectious Immunology 49:571-575,1985.

14. Mathews RC Pathogenicity determinants of Candida albicans: potential targets for immunotherapy? Microbiology 140:1505-1511, 1994

15. Merz WG. Candida albicans strain delineation. Clinical Microbioliology Reviews 3:321-334, 1990.

16. Morace G, Archibucci C, Sestito M. Polonelli L. Strain differentiation of pathogenic yeast by the killer system. Mycopathologia 84:81-85, 1984.

17. Muller J, Kappe R, Kubitza D, Fesler R, Scheidecker $J$. The incidence of deep seated mycoses. Mycoses 31(suppl 1):9-28, 1987.

18. Odds FC, Webster CE, Mayuranathan P, Simmons PD. Candida concentrations in the vagina and their association with signs and syntoms of vaginal candidosis. Journal of Medical and Veterinary Mycology 26:277-283, 1988.

19. Polonelli L, Archibusacci C, Sestito M, Morace G. Killer system:a simple method for differentiating Candida albicans strains. Journal of Clinical Microbiology 17:774-780, 1983.

20. Price MF, Wilkinson ID, Gentry LO. Plate methods for detection of phospholipase activity in Candida albicans. Sabouraudia 20:7-14, 1982.

21. Ruchel J, Tegeler R, Trost MA. Comparison of secretory proteinases from differents strains of Candida albicans. Sabouraudia 20:233-244, 1982.

22. Ruchel R, Uhlemann K, Böning B Secretion of acid proteinase by different species of the genus Candida. Zentralblatt Für Bakteriologie und Hygiene A. 255:537-548, 1983.

23. Ruchel R, De Bernardis F, Ray TL, Sullivan PA, Coleg GT. Candida acid proteinases. Journal of Medical and Veterinary Mycology 30 (suppl 1):123-132, 1992.

24. Samaranayake LP, Raeside JM, MacFarland TW. Factors affecting the phospholipase activity of Candida species in vitro. Sabouraudia 22:201-207, 1984.

25. Shimizu K, Kondoh Y, Tanaka K. Proteinase production and pathogenicity of Candida albicans: I. Invasion into choriallantoic membrane by $C$. albicans of different proteinase activity. Microbiology Immunology 31:1045-1060, 1987.

26. Staib F. Serum proteins as nitrogen source for yeastlike fungi. Sabouraudia 4:187-193, 1965.

27. Woods DR, Bevan EA. Studies on the nature of the killer factors produced by Saccharomyces cerevisae. Journal of General Microbiology 51:115-126, 1968. 